\title{
An assessment of the implementation of the provincial cervical screening programme in selected Primary Health Care Clinics in the Ilembe region, KwaZulu-Natal
}

\author{
MN Sibiya, M Tech: Nursing \\ Durban University of Technology \\ L Grainger, PhD \\ Durban University of Technology
}

Correspondence address:

Nokuthula Sibiya

Durban Institute of Technology

PO Box 1108

Seaglen Gardens

4146

Tel : (031) 204-2687

Fax : (031) 204-2039

E-mail : nokhutulas $(a)$ dut.ac.za

\begin{abstract}
Curationis 30(1): 48-55
Cervical cancer is almost completely preventable, yet it is the second most prevalent cancer amongst women in South A frica. KwaZulu-Natal $(\mathrm{KZN})$ in particular has a high mortality rate of cervical cancer and $1: 40$ women die from cancer of the cervix. Therefore, in 1997 a cervical screening policy and programme was implemented in the province. The purpose of the study was to evaluate the implementation of selected aspects of the Provincial cervical screening programme in selected Primary Health Care (PHC) clinics in Ilembe Region, KZN.
\end{abstract}

Results indicated that there was a lack of resources needed for implementing the programme in rural clinics compared to urban clinics. However, all clinics in the study had an adequate supply of the drugs needed for the treatment of abnormal smears. On reviewing the records, the researcher noted that most of the results indicated that smears had adequate cells needed for analysis. However, the results indicated that there was a problem with follow-up of clients with abnormal smears. Feedback to the clinics from the referral hospital regarding the outcome of the visit was inadequate. The results indicated that the mechanisms of record keeping were inadequate. Therefore, the above results indicate that problems exist at the selected PHC clinics that may result in ineffective implementation of the cervical screening programme.

\section{Acknowledgements}

I would like to acknowledge with gratitude the following people who contributed to the success of this study:

- Professor L Grainger for her scholarly guidance, support and encouragement

- $\quad$ Professor NS Gwele for her support, understanding and guidance

- Professional nurses at the clinics where this study was conducted for their co-operation throughout the study

- All those who in one way or another, contributed to my research work. 


\section{Introduction}

Cervical cancer is an important women's health problem in developing countries, killing some 200,000 women each year. It is the third most common cancer overall and the leading cause of death from cancer among women in such countries. At least 370,000 new cases are identified globally each year and $80 \%$ are in developing countries. (Tinker, 1999: 1-3.) In South Africa cervical cancer is now the second most common cancer amongst women. A total of 5318 new cases of cervical cancer were reported in 1997, comprising 18,2\% of cancers reported. The risk of developing cervical cancer among South African women is 1:29 (Cancer Association of South Africa, 2004: 1-3) (CANSA). Cervical cancer is the most common cancer in Black $(31,2 \%)$ and Coloured $(22,9 \%)$ women, followed by Asian $(8,9 \%)$ and White $(2,7 \%)$ women. (Sitas, Madhoo and Wessie, 1999: 15) (Adar and Stevens, 2000): 424.) From this data, it can be seen that this disease occurs more often among A frican women. This is further supported by the study that was done by de Jonge, Makin and Lindeque (1999: 44) which indicated a more aggressive tumour in black women compared to white women with cervical cancer in South $\Lambda$ frica.

Cervical cancer has been described as "a disease of the economically disadvantaged" because even in developed countries such as the United States, cervical cancer mostly affects women of low socio-economic status, rural and poor women (Dickson-Tetteh, 1999: 18-20). Lower socio-economic status has been associated with higher risk of developing cancer probably due to lack of access to good health care and screening programmes (Mqoqi, 2003: 14). This is further supported by Smit, Beksinska, Ramkissoon, Kunene and Penn-Kekana (2004: 78) who state that in South Africa, over $90 \%$ of White women and about $5 \%$ of African women had accessed cervical cancer screening in the past 10 years, reflecting the inequity in access.

Cervical cancer, a preventable cause of death, accounts for nearly $2 \%$ of deaths of women aged $15-44$ years and $4 \%$ of women aged 45-59 years (Adar and Stevens, 2000: 124). According to the study that was done by de Jonge, Makin and Lindeque (1999: 44), black women presented late with an advanced stage of the disease and late presentation in black women is an issue which is dictated by unfavourable socio-economic variable. Lack of cancer awareness and knowledge amongst the black population and ongoing inequities in opportunistic screening were pivotal to this situation. This is further supported by the findings of the study that was done at King Edward Hospital, Durban by the Hypertension Unit of the Medical Research Council that revealed that $65 \%$ of women questioned had no knowledge about this form of cancer or about pap smears (Leeman: 1-2: 2002).

KwaZulu-Natal (KZN) has the highest incidence of cervical cancer in South Africa. This province in particular, has a high mortality rate of cervical cancer and $1: 40$ women will die from cancer of the cervix (Department of Health, 20(0)). KZN has a cervical screening policy, which aims to detect women at risk of developing cancer. The cervical screening policy states that cervical screening will be available to all women from the age of 30 years at intervals of ten years provided no smears have been taken within the previous five years. It also stipulates that women of any age with a visible cervical abnormality and those that have risk factors, for example, post-coital bleeding and repeated sexually transmitted infections (STIs) should have a Pap smear taken. This policy is based on the national cervical screening policy, which was developed by taking into account the models of the natural history of the disease. The explicit objectives are to reduce the incidence of cervical cancer, the morbidity and mortality associated with the disease, and ultimately the amount of money spent on the treatment of invasive cancer. A protocol for the implementation of the policy has been developed and this is intended to form the basis of the cervical screening policy for KZN (KZN Department of Health, 1999: 7-9).

\section{Problem statement}

No country in the developing world has ever successfully established mass cervical screening programmes. There are many reasons for this, including the demands of competing health needs, such as malaria, tuberculosis and HIV, the lack of a well-developed primary health care $(\mathrm{PHC}$ ) infrastructure, limited human. financial and technical resources and the diversion of resources that occurs in areas where war and civil strife tend to be endemic (Denny, 2000: 24-25). According to Dickson-Tetteh (1998: 1820 ), screening efforts in developing countries have had only limited success for a number of reasons including:

\section{- limited screening services; \\ - failure of the programmes to target or to reach at risk women; \\ - $\quad$ limited frequency of screening; \\ - $\quad$ inadequate laboratory and treatment services; \\ - inadequate number of trained personnel; \\ - $\quad$ inadequate Pap smear supplies; \\ - difficulty in client follow-up; \\ - $\quad$ high cost of services; \\ - limited awareness of cervical cancer as a health problem; and \\ - $\quad$ cultural obstacles to providing services.}

In South Africa, according to the study that was done by Michelow, Wright, Mayet and Leiman (1999: 36-39) on the evaluation of the interim cervical screening programme in the greater Johannesburg metropolitan area, reasons for the failure of cervical screening programme included:

- $\quad$ insufficient numbers of smears
taken;
lack of education in the target
population who do not present
for smears nor return for results;
a mobile target population
making follow-up difficult;
confusion over whose
responsibility is to follow-up
patients resulting in
unacceptable follow-up rates of
positive cases;
clinic health workers who
themselves do not view
screening as important and
therefore, do not promote its
use;
inadequate resources available
for sereening;
sub-optimal management of
patients within the referral
hospital; and
poor communication between
clinic, laboratory and referral
hospital.
It is now for years since the
KZN cervical screening policy
came into existence, yet no
empirical evidence exists with
regard to the process of
- $\quad$.

49

Curationis March 2007 


\section{Purpose of the study}

The purpose of the study was to evaluate the implementation of selected aspects of the Provincial cervical screening programme in selected Primary Health Care clinics in Ilembe Region, KZN.

\section{The objectives of the study}

The objectives of the study were to determine the nature and adequacy of available resources, availability of treatment for clients with abnormal smears, useability of smears taken, follow-up of clients who were diagnosed with abnormal smears, referral process and record keeping.

\section{Significance for the study}

Cancer of the cervix is preventable if detected early by a Pap test screening and when diagnosed early, it can be cured (Denenberg, 1997: 1-13). By the time there are physical symptoms such as bleeding and pain, the disease could be at an advanced stage. It is, therefore, vital for all women, regardless of their age, to have a regular Pap test (CANSA, 1994: 6). If not detected early, treatment of invasive cancer can cost an average of R53 000.00 per patient. The treatment is not always available, so a woman may only be offered two treatments and then sent home to die (Department of Health, 2000). This is not acceptable and can be avoided. The success of the screening programme in reaching its aims is dependent on achieving adequate coverage. While the screening programme will be introduced incrementally depending on health service capacity, the ultimate goal is to screen at least $70 \%$ of women, nationally, within the target age group within 10 years of initiating the programme (KZN Department of Health, 1999: 9.) Therefore, effective, ongoing monitoring, evaluation and support for the implementation and sustainability of the screening programme will not only benefit women of South Africa, but the country as a whole.

\section{Operational definitions}

Terms were defined following the pattern of literature review.

Adequate smear - smear that contains both ect- and endo- cervical cells, cervical mucus and minimal amounts of blood, pus and debris (KZN Department of Health, 1999: 15)

Useability of smear - smear that is adequate in that it contains the cells needed for analysis in the laboratory in order to accurately identify an abnormal smear

Abnormal smear - smear that is classified as low-grade squamous intraepithelial lesion or high grade intraepithelial lesion which requires followup and referral for colposcopy (KZN Department of Health, 1999: 14)

Urban Clinies - clinics that are situated in the townships

Rural Clinics - clinics that are situated outside the township

Resources - equipment that is used for taking Pap smears

Adequate resources - clinics that have all the equipment needed for implementing the cervical screening programme in relation to the number of patients seen per day (see appendix 1 for criteria for adequacy)

\section{Literature review}

Cancer of the cervix develops over time from a precursor lesion, which, although seemingly invisible to the naked eye, can be diagnosed by special investigations for example, cervical cytology, also known as Pap smear. Pap smear is not usually diagnostic and it requires appropriate investigative follow-up and treatment. According to KZN Department of Health (1999: 38), clients with abnormal Pap test results need to have additional tests (colposcopy and biopsy) to find out whether a pre-cancerous change or cancer is present. Furthermore the cervical screening protocol maintains that a working follow-up system needs to be in place for effective implementation of the cervical screening programme. The protocol states that the time lapse between screening and follow-up should be 1-4 weeks depending on the circumstances and every attempt possible should be made to find those patients who do not return voluntarily.

According to Dickson-Tetteh (1998: 1820) screening efforts in developing countries have had only limited access for a number of reasons. One of the reasons is the difficulty in client follow- up. This could be related to the fact that some of the clients do not have proper addresses and telephone numbers because they are from informal settlements. Another fundamental problem with the service is that it does not have an accurate computerized database to enable follow-up to be done (Kerr, 1995: 26-29). For instance, in South Africa, according to the study that was done by Zweigenthal (1998) an attempt was made to follow-up the vast majority (74\%) of clients with high-grade lesions. Only $66 \%$ of these attempts were successful.

The protocol states that a good referral system should also be in place to ensure effective implementation of the programme. There should be effective liaison with referral centres for diagnosis and treatment to ensure effective followup and monitoring. According to KZN Department of Health (1999: 38-39) clinics are expected to request feedback to maintain client profile. According to the study that was done by Zweigenthal (1998), the results showed that all patients were encouraged to report back to the clinic to give information as to the outcome of their hospital visit. This was the only way the feedback of a referral hospital was gained, as the colposcopy clinics did not send a report of their findings to the clinics.

It is crucial for the effectiveness of any screening programme that women recommended for repeat Pap smear receive their results, and return to the clinic for follow-up. To this end, every clinic must have an effective mechanism of record keeping, record maintenance and recall. Currently, some clinics have no record keeping protocol, and amongst those who do, quality varies (Smith and Hoffman, 2000). According to the study that was done by Kerr (1995: 26-29), the results revealed that the service did not have an accurate computerized database to enable the target population to be invited for screening and follow-up. Unless service authorities are able to improve their age-sex information significantly, the call and recall system will never be truly effective.

\section{Methodology}

This study took the form of formative evaluation research. The target population consisted of $\mathrm{PHC}$ clinics in $\mathrm{KZN}$ that had implemented the cervical screening policy and the programme. A 
three-stage selection plan was applied to select the sample from the accessible population. The accessible population consisted of the clinics in the Ilembe region that refer clients to the secondary hospital. There were 15 clinics that refer to the hospital and out of these clinics, 10 were situated in urban areas and five in rural areas. Therefore, four clinics from a total of 15 constitute $27 \%$ of the population. The first stage of the selection involved a random selection of two clinics from urban areas, which were indicated as clinic A and clinic B and two from rural areas indicated as clinic $\mathrm{C}$ and clinic D.

Within each of the selected clinics, the evidence for the evaluation of the implementation of the cervical screening programme was sampled. Therefore, the second stage of selection was the selection of records. A purposive sample consisted of all records of clients who were diagnosed with abnormal smears as from $1^{\text {st }}$ January 2001 to $30^{\text {th }}$ September 2001 to assess follow-up. A total of 88 records of clients with abnormal smears out of 206 clients taken smears were analyzed. This constituted $42,7 \%$ of the records.

Lastly, the third stage involved the selection of all consenting Professional Nurses from each of the selected clinics. The sample consisted of 14 Professional Nurses from the two urban clinics and seven from the two rural clinics. Two focus group discussions were held at clinic $A$ and the first group consisted of three Professional Nurses. One focus group discussion was held at clinic B and six Professional Nurses participated in the study. Other nurses were not available at the time of the discussions. Only one discussion was done in rural clinics because of limited number of nurses. Five Professional Nurses from clinic $C$ participated in the study and only two participated at clinic $D$ because one Professional Nurse was off sick. Therefore, 21 Professional Nurses out of a total of 39 participated in the focus group discussion. This constituted $53,8 \%$ of the population.

\section{Data collection and analysis}

When collecting data, the researcher made use of three methods. The first involved the clinic audit. An audit of the clinic was carried out at each of the four selected clinics. Data on available equipment and consultation rooms that were used for taking smears were collected by means of the audit checklist. The audit checklist was developed from the protocol for the cervical cancer screening program for KZN. Specifically the clinic audit checklist focused on the adequacy of the number of the consulting rooms in relation to the number of the patients seen in the clinic, equipment for taking smears e.g. vaginal speculum, linen, including screens for patient's privacy, sterilizing equipment and other equipment essential for infection control.

The second method used for data collection was a record review using a checklist developed by the researcher based on the KZN cervical screening programme. A retrospective analysis of records was done in order to assess the follow-up of clients who were diagnosed with abnormal smears, useability of smears taken and referral process.

The third method used for data collection was focus group discussions that were conducted at each clinic with the aim of obtaining information about the perceptions of the clinic staff regarding a cervical screening programme. An interview guide was used to obtain information from nurses. Data obtained from the clinic audit and record review were analysed by means of descriptive statistics. Data obtained from the focus group discussions were analysed using the provincial guidelines for cervical screening.

\section{Reliability and validity}

No specific procedures were conducted to test the reliability of the observation and audit checklists. However, method triangulation was employed to ensure credibility of the results. The researcher in this study used multiple sources and perspectives namely audit check, record review and focus group discussions. Validity of the data collection instruments was ensured by subjecting the instruments to a cervical screening expert familiar with the programme under study. Furthermore, construct validity was ensured by aligning the content of the audit checklist and observation tools with the protocol for the cervical screening programme for KZN. A pilot study was done to test feasibility of the study including clarity of questions in the interview guide.

\section{Ethical considerations}

Prior to the commencement of the study, the researcher obtained written permission to undertake the study from the KZN Department of Health and Chief Medical Superintendent of the referral hospital. The researcher made it a priority to ensure protection of the rights of the participants in this study by ensuring that the ethical principles based on the Guidelines for the Ethical Conduct of Research at Technikon Natal (2000: I-29), were considered throughout the study. When reviewing clinic records in order to assess follow up of clients with abnormal smears, the researcher ensured anonymity of clients by the process of complete de-identification. The identifiers were removed permanently and the numbers were allocated. The Professional Nurse in-charge of the clinic made a photocopy of records after concealing the names of the clients so that the researcher was unable to link the information from records with the client. The researcher obtained written consent from the nurses that participated in the focus group discussions.

\section{Results and discussion}

\section{Availability of resources}

The results indicated that in some clinics there was a lack of necessary equipment for the effective implementation of the cervical screening programme. In some clinics even though the equipment was available, it was seldom in working order. This was observed in rural clinics compared to urban clinics. This was an understandable result. In fact, in one rural clinic although most of the clinic was available and adequate, taking of pap smears had not been carried out for nine months at the time of data collection, due to a broken steriliser. As mentioned in the sampling section of the study, it was expected that urban clinics would be better resourced compared to rural clinics. Such an expectation, however, does not undermine the importance of adequately resourced health care facilities for the effective implementation of a national and provincial policy such as the one under study. According to the study that was done by Smith and Hoffman (2000), the results indicated that improving the availability of equipment, particularly the specula and sterilisers would facilitate a rise in screenings performed. All the clinics were observed to have an adequate supply of drugs for the treatment of abnormal smears. These 
Table 1: Summary of clinic audit findings

\begin{tabular}{|c|c|c|c|c|}
\hline EQUIPMENT & $\begin{array}{l}\text { CLINICA } \\
\text { URBAN }\end{array}$ & $\begin{array}{l}\text { CLINIC B } \\
\text { URBAN }\end{array}$ & $\begin{array}{l}\text { CLINICC } \\
\text { RURAL }\end{array}$ & $\begin{array}{l}\text { CLINICD } \\
\text { RURAL }\end{array}$ \\
\hline Number of consulting rooms & Adequate & Inadequate & Adequate & Adequate \\
\hline Curtains/ Screens & Adequate & Adequate & Adequate & Adequate \\
\hline Drugs for treatment & Adequate & Adequate & Adequate & Adequate \\
\hline Cusco vaginal speculum & Adequate & Adequate & Adequate & Inadequate \\
\hline Aylesbury sputulum & Adequate & Adequate & Adequate & Adequate \\
\hline Glass specimen slides & Adequate & Adequate & Adequate & Adequate \\
\hline Cytological fixative & Adequate & Adequate & Adequate & Adequate \\
\hline Cytology lab forms & Adequate & Adequate & Adequate & Adequate \\
\hline Water for lubricating speculum & Adequate & Adequate & Adequate & Adequate \\
\hline Paper hand towel for draping & Adequate & Adequate & Adequate & Adequate \\
\hline I amp & Adequate & Adequate & Adequate & $\begin{array}{l}\text { Adequate but no } \\
\text { globe for } 3 \text { months }\end{array}$ \\
\hline Couch & Adequate & Adequate & Adequate & Adequate \\
\hline Sheets/ Draw sheets & Adequate & Adequate & Adequate & Adequate \\
\hline Linen protector & Adequate & Adequate & Adequate & Adequate \\
\hline Bucket with disinfectant & $\begin{array}{l}\text { Adequate with } \\
\text { correct disinfectant }\end{array}$ & $\begin{array}{l}\text { Adequate with } \\
\text { correct disinfectant }\end{array}$ & $\begin{array}{l}\text { Adequate with } \\
\text { correct disinfectant }\end{array}$ & $\begin{array}{l}\text { Not prepared - no } \\
\text { smears were taken }\end{array}$ \\
\hline Gloves & Adequate & Adequate & Adequate & Adequate \\
\hline Autoclave/Steriliser & $\begin{array}{l}\text { Good working } \\
\text { condition }\end{array}$ & $\begin{array}{l}\text { Good working } \\
\text { condition }\end{array}$ & $\begin{array}{l}\text { Good working } \\
\text { condition }\end{array}$ & $\begin{array}{l}\text { Not available, sent } \\
\text { for repairs }\end{array}$ \\
\hline
\end{tabular}

data were corroborated by the information obtained from the focus interviews. All focus groups concurred that they had enough supply of drugs for treating clients with abnormal smears. The success of such treatment, however, is not always known and the follow up data revealed serious gaps in that aspect of the screening programme. Therefore, one can assume that the availability of treatment for abnormal smears would have a positive impact on preventing and controlling cancer of the cervix. Data on availability of resources appears in Table 1

\section{Management of clients with abnormal Pap smears}

It should be recalled that clinic D was not conducting any cervical screening at the time of data collection. Hence the results on the management of clients with abnormal smears are based on the data obtained from two urban and one rural clinic. Within the context of this study, variables of interest with regard to management of clients with abnormal Pap smears were age, contact details, laboratory number, summary of Pap smear results, attempt to contact client, useability of smear, communication of the results to the client, appropriate referral arrangements, feedback from the referral institution and feedback from the client.

All three clinics were found to be doing well in implementing the provincial programme for cervical screening in at least five of the variables of interest in the study. These variables were documenting the patient's age, laboratory number, summary of pap smear results, feedback from clients and useability of pap smears. With regard to two of the five variables, however, that is useability of smears and feedback from clients only two of the clinics demonstrated more than $70 \%$ of implementation. The department of health guidelines indicate that the adequacy of a screening facility should be at least $70 \%$. It would seem, therefore, for the clinics included in this study, criteria of success were achieved. It is not known, however, whether or not the clinic that did not record its Pap smear useability, did not in fact achieve the 70\% useability criteria. Kerr (1995: 26 - 29) 


\begin{tabular}{|c|c|c|c|c|}
\hline RECORD DETAILS & $\begin{array}{l}\text { CLINICA } \\
\text { URBAN }\end{array}$ & $\begin{array}{l}\text { CLINIC B } \\
\text { URBAN }\end{array}$ & $\begin{array}{l}\text { CLINICC } \\
\text { RURAL }\end{array}$ & $\begin{array}{l}\text { CLINIC D } \\
\text { RURAL }\end{array}$ \\
\hline Age & $100 \%$ & $100 \%$ & $100 \%$ & $\begin{array}{l}\text { No screening done } \\
\text { at the time of data } \\
\text { collection }\end{array}$ \\
\hline Contact details & $37.5 \%$ & $57,6 \%$ & $57,1 \%$ & $\begin{array}{l}\text { No screening done } \\
\text { at the time of data } \\
\text { collection }\end{array}$ \\
\hline Laboratory number & $100 \%$ & $100 \%$ & $100 \%$ & $\begin{array}{l}\text { No screening done } \\
\text { at the time of data } \\
\text { collection }\end{array}$ \\
\hline $\begin{array}{l}\text { Summary of abnormal Pap smear } \\
\text { results }\end{array}$ & $100 \%$ & $100 \%$ & $100 \%$ & $\begin{array}{l}\text { No screening done } \\
\text { at the time of data } \\
\text { collection }\end{array}$ \\
\hline Attempt to contact client & $8,3 \%$ & $34,6 \%$ & $25 \%$ & $\begin{array}{l}\text { No screening done } \\
\text { at the time of data } \\
\text { collection }\end{array}$ \\
\hline Useability of smear & $95 \%$ & Not recorded & $75 \%$ & $\begin{array}{l}\text { No screening done } \\
\text { at the time of data } \\
\text { collection }\end{array}$ \\
\hline Results communicated to the client & $8,3 \%$ & $34,6 \%$ & $21,4 \%$ & $\begin{array}{l}\text { No screening done } \\
\text { at the time of data } \\
\text { collection }\end{array}$ \\
\hline Appropriate referral arrangements & No referral needed & $100 \%$ & $100 \%$ & $\begin{array}{l}\text { No screening done } \\
\text { at the time of data } \\
\text { collection }\end{array}$ \\
\hline $\begin{array}{l}\text { Feedback from the referral } \\
\text { institution }\end{array}$ & No referral necded & $0 \%$ & $0 \%$ & $\begin{array}{l}\text { No screening done } \\
\text { at the time of data } \\
\text { collection }\end{array}$ \\
\hline Fecdback from the client & No referral needed & $100 \%$ & $82,1 \%$ & $\begin{array}{l}\text { No screening done } \\
\text { at the time of data } \\
\text { collection }\end{array}$ \\
\hline
\end{tabular}

identifies monitoring of the proportion of adequate smears as an important variable for the internal and external quality control.

One clinic had no documented evidence of obtaining patient feedback and one had no documented evidence on the useability of pap smears. Attempt to contact clients and communicating results to the clients was evident in less than $35 \%$ of all records reviewed in all three clinics. That the attempt to communicate the results was low, ranging from 8 to $35 \%$ could be attributed to the fact that none of the clinics included in the study had $100 \%$ record of patients' contact details. In fact, only $57 \%$ of documents had complete patient contact details in two of the clinics, whilst this was at $37,5 \%$ for the remaining clinic. These findings are even worse compared to those reported by Zweigenthal (1998) where an attempt was made to follow-up the vast majority (74\%) of clients with high-grade lesions, and $66 \%$ of these attempts were successful. For the current study, when nurses were asked during the interviews about problems they experienced in contacting clients with abnormal smears, the following response was obtained:

"Patients usually give us incorrect contact details and they do not inform us about change of address..."

None of the 88 reviewed documents showed evidence of feedback from the referral hospital. Interview data with nurses revealed that none of the referral hospital provided feedback to the referral hospital. Lack of feedback from a referral hospital is substantiated by the following extract from an interview:

"No feedback is given to the clinic except if the client comes back for the next visit..."

This means that there was lack of effective liaison with referral centres for diagnosis and treatment to ensure follow-up and 
monitoring. According to Smith and Hoffman (2000) nurses work diligently to achieve good rates of follow-up but there is one group of women that they cannot monitor, namely those with high-grade lesions. Once a woman is referred for colposcopy, the nurses do not receive feedback regarding whether she kept her appointment, or what the outcome was. This is further supported by the findings of a study that was done by Wood and Jewkes (1996) where the health workers expressed disappointment that they continued to not receive feedback from hospital specialists to whom they referred women found to have abnormal smears, which merited further clinical investigations. The only way that feedback of a referral to a hospital was gained was that all patients were encouraged to report back to the clinic to give information as to the outcome of their hospital visit. Improving communication would allow the nurses to remain involved with their clients, and help to ensure that follow-up takes place. The referring doctor has a responsibility to the woman to ensure that she has fully understood the significance of her abnormal smear, the options for evaluation and management of that smear, and has been involved in the decisionmaking (National Health and Medical Research Council, 1993).

\section{Conclusion and}

\section{recommendations}

The results indicated that follow-up of clients with abnormal smears was not always carried out. It is recommended that women should be motivated to come back for their results after a certain period to facilitate follow-up. This will ensure co-operation from a woman. The researcher also noted that few clients were referred to the hospital because of problems with follow-up. The results also showed that two of the three clinics included in the study had a $100 \%$ referral rate. One clinic, however, did not have any documented evidence of having referred patients with abnormal smears to any hospital. It is not clear, however, how clinics recorded less than $100 \%$ referral could have failed to communicate results to clients. Records showed that communicating results to clients was not always carried out, ranging from $8,3 \%$ to $34,6 \%$. In the case of those clients that were successfully referred, no feedback was given to the clinics, which is not in accordance with the cervical screening programme. The only way that the clinics received the feedback was through the clients that reported back to the clinics as to the outcome of their hospital visit. It is recommended that the Provincial task team that is responsible for monitoring the programme and the policy should review the communication system between the clinics and the referral hospitals. Nurses should also put more effort by persuading the referral hospital to provide feedback.

The results also indicated that a good mechanism for record keeping was lacking. It is therefore, recommended that a good, reliable health information system be introduced to maintain records of smear results. This could take the form of a computer-based system or a dedicated person who as a part of his/ her normal duty, checks, records and follows-up abnormal smear results. An integrated, computerised system linking hospitals, clinics and laboratories would achieve this.

One can conclude by indicating that there are problems with the implementation of the cervical screening programme in KZN. The Provincial Department of Health needs to ensure that there are adequate facilities for the implementation of the cervical screening programme. Otherwise, this province is still going to experience a high prevalence rate of cancer of the cervix. Training and educating nurses in the technique of taking Pap smears appeared to have had a favourable outcome. Nurses however, need to put more effort into the implementation of the programme, specifically with regard to communicating the results to clients, obtaining feedback from the referral hospitals and adequate record keeping. The important aspect of the systematic follow-up of records, with particular emphasis on abnormal smears cannot be overemphasised. This is further supported by Smit, et al. (2004: 78) where it is stated that key challenges in translating national policy into effective service delivery include inadequate allocation of resources, limited numbers of trained service providers in public sector facilities, limited capacity of national cytological laboratories and improving referral and feedback of abnormal smears.

\section{References}

ADAR, J \& STEVENS, M 2000: South African Health Review 2000. Durban:
Health Systems Trust.

CANCER ASSOCIATION OF SOUTH AFRICA (CANSA) 2004: Cervical Cancer. Available from: http:// www.cansa.org.za.

CANSA, 1994: A Cervical Population Screening Programme for South Africa, (Unpublished): Johannesburg.

De JONGE, ETM; MAKIN, JD \& LINDEQUE, BG 1999: Is cancer of the cervix a more aggressive disease in black women? The South African Journal of Epidemiology and Infection, 14(2): 40-45.

DENENBERG, R 1997: Cervical cancer and women with HIV. GMHC Treatment Issues, 11(7/8).

DENNY, I 2000: Khayelitsha cervical cancer screening project. Women's Health Project Newsletter, 34: 24-25.

DEPARTMENT OF HEALTH, 2000: Cancer of the cervix (Letter). KwazuluNatal: Department of Health.

DICKSON-TETTEH, K 1998: Cervical cancer: A global health problem. Health and Hygiene, January: 18-20.

HOYTT, MJ 1998: Cervical Dysplasia and Cancer. Community Research Initiative on AIDS, 7(2). Available from: http://www.thebody.com/cria/spring $98 /$ dyspalsia.html.

KERR, J 1995: Cervical Cancer: Improving the Service. Nursing Standard, 9(14): 26-29.

KZN DEPARTMENT OF HEALTH 1999: Cervical and Breast Cancer Screening Programme. KwaZulu-Natal: Department of Health.

LEEMAN, P 2002: Women still in the dark about Cervical Cancer. Available from: http://www.hst.org.za.

MICHELOW, PM; WRIGHT, NT; MAYET, NT \& LEIMAN, G 1999: Evaluation of the Interim Cervical Cancer Screening Programme in the Greater Johannesburg Metropolitan Area. The South African Journal of Epidemiology and Infection, 14(2): 36-39.

MQOQI, N 2003: National Department of Health Systems Research, Research Co-ordination and Epidemiology. 
Research Update, 5(4). Available from http://www.doh.gov.za/docs/research.

NATIONAL HEALTH AND MEDICAL RESEARCH COUNCIL, 1993: Screening to Prevent Cervical Cancer: Guidelines for the Management of Women with Screen Detected Abnormalities. Canberra: Australian Government Publishing Service.

SITAS, F; MADHOO, J \& WESSIE, J 1998: Cancer in South Africa, 1993-1995. Johannesburg: National Cancer Registry of South Africa.

SMIT, J; BEKSINSKA, M; RAMKISSOON, A; KUNENE, B \& PENN-KEKANA, L 2004: South A frican Health Review 2003/2004. Durban: Health Systems Trust.

SMITH, N \& HOFFMAN, M 2000: A Situation Analysis of Cervical Cancer Screening in Mitchell's Plain Health District. Unpublished Masters in Public Health. University of Cape Town.

TECHNIKON NATAL, 2000: Guidelines for the ethical conduct of research at Technikon Natal. Technikon Natal.

TINKER, A 1999: Worldwide Cervical Cancer Issues [online]. Available from: http://www.nccc-online.org/worldcancer.

ZWEIGENTHAL $V$ 1998: An Assessment of the Effectiveness of the Implementation of the Cervical Screening Following Policy Guidelines into the Routine Services of the Eastern Metropolitan Local Council. The South African Institute for Medical Research: University of Witwatersraand, Johannesburg.
Appendix 1: Criteria for adequacy of equipment used for taking pap smears for 10 patients seen per day by two professional nurses

\begin{tabular}{|l|l|}
\hline EQUIPMENT & NUMBER \\
\hline Number of consulting rooms & 2 \\
Curtains/ Screens & 2 \\
Cusco vaginal speculum & 10 \\
Aylesbury sputulum & 10 \\
Glass specimen slides & 10 \\
Cytological fixative & 2 tins \\
Cytology lab forms & 10 \\
Water for lubricating speculum & 2 taps \\
Paper hand towel for draping & 10 \\
Lamp & 2 \\
Couch & 2 \\
Sheets/ Draw sheets & 10 \\
Linen protector & 10 \\
Bucket with disinfectant & 2 \\
Gloves & 10 pairs \\
Autoclave/ Steriliser & 1 \\
\end{tabular}

